\title{
Masa Tenisi Sporcularının Problem Çözme Becerileri İle Ego Durumları Arasındaki İlişkinin İncelenmesi: Türkiye Masa Tenisi Federasyonu Süper Lig Örneği
}

\section{Investigation of The Relationship Between Problem Solving Skills and Ego States of Table Tennis Athletes: Turkey Table Tennis Federation Super League Sample}

Öz

\author{
Vedat ERIM1, Fatih Samet ATASOY², Soner ÇANKAYA ${ }^{3}$
}

Araştırmanın amacı, Türkiye süper liginde müsabık masa tenisi sporcularının problem çözme becerileri ile ego durumları arasındaki ilişkiyi bazı demografik değişkenler açısından incelemektir. Araştırma evrenini 2018-2019 sezonunda Türkiye Masa Tenisi Federasyonu Süper Ligi'nde müsabık sporculardan ( $n=70$ ) oluşmaktadır. Tüm sporcular ulaşılabilir olması ve evreni oluşturan sporcu sayısının sınırlı olması (az) nedeni ile çalışmada tam sayım tekniği kullanılmıştır. Araştırmada sporcuların ego durumlarını belirlemek için geçerlilik, güvenirlilik ve standardizasyonu yapılmış "Ego Durumları Ölçeği (EDÖ)", Problem çözme becerilerini belirlemek için geçerlilik ve güvenirliliği yapılmış "Problem Çözme Envanteri (PÇE)" ve onların demografik ve sporcu özelliklerine ait bilgileri elde etmek için "Kişisel Bilgi Formu" kullanılmıştır. Araştırmaya katılan sporcuların eğitimi, cinsiyet ve milli sporcu olup olmamalarına göre sporcuların ego durumlarına ait (Eleştirel Ebeveyn (EE), Koruyucu Ebeveyn (KE), Yetişkin (Y), Doğal Çocuk (DÇ) ve Uygulu Çocuk (UÇ)) toplam puanlar arasındaki farklıılılar Tek Yönlü Varyans Analizi (One-way ANOVA) ve Tukey çoklu karşılaştırma testi ile analiz edilmiştir. Sporcuların problem çözme becerileri ile onların ego durumları arasındaki ilişki ise Pearson Korelasyon Katsayısı ile incelenmiştir. Araştırmada masa tenisi sporcularının $Y$ ve DÇ ego durumları ile Aceleci Yaklaşım (AY) ve Kaçıngan Yaklaşım (KY) alt boyutları arasında pozitif bir ilişki içinde olduğu tespit edilmiştir. $\mathrm{Bu}$, masa tenisi sporunun sporcuları üzerindeki bir etkisi olarak görülebilir. Fakat kuramsal temel açısında çelişkili bir durumun göstergesi olduğunun da altını çizmek gerekir.

Anahtar Kelimeler: Masa tenisi, transaksiyonel analiz, ego durumları, problem çözme becerisi

\section{Abstract}

The aim of this study is to examine the relationship between problem solving skills and ego states of table tennis athletes in Turkish super league in terms of some variables. Population consists of athletes in Turkish Table Tennis Federation Super League during the 2018-2019 season $(n=70)$. Total population sampling method was used since all athletes were available and number of athletes was limited. "Ego States Scale" was used to find out ego states, "Problem Solving Inventory" was used to find out problem solving skills and "Personal Information Form" was used for demographic and sporting information. Differences between total scores of athletes' ego states (Critical Parent (CP), Nurturing Parent (NP), Adult (A), Free Child (FC) and Adapted Child (AC)) according variables of educational status, gender and being a national team athlete were analysed with One-way ANOVA and Tukey multiple comparison test. Correlation between athletes' problem solving skills and ego states was analysed with Pearson correlation coefficient. A and FC ego states of athletes were found to be positively correlated with Impulsive Style (IS) and Avoidant Style (AS) sub-dimensions. This can be an effect of table tennis sport on athletes. However, it should be emphasized that it is an indicator of a negative situation in terms of theoretical basis.

Keywords: Table tennis, transactional analysis, ego states, problem solving skills

${ }^{1}$ Ondokuz Mayıs Üniversitesi, Yaşar Doğu Spor Bilimleri Fakültesi, Samsun, Türkiye, https://orcid.org/0000-0003-4548-0047 ${ }^{2}$ Ondokuz Mayıs Üniversitesi Sosyal Bilimler Enstitüsü, Samsun, Türkiye, https://orcid.org/0000-0002-8071-6601

${ }^{3}$ Ondokuz Mayıs Üniversitesi, Yaşar Doğu Spor Bilimleri Fakültesi, Samsun, Türkiye, https://orcid.org/0000-0001-8056-1892

Atıf / Citation: Erim, V., Atasoy, F. S., \& Çankaya, S. (2020). Masa tenisi sporcularının problem çözme becerileri ile ego durumları arasındaki ilişkinin incelenmesi: Türkiye masa tenisi federasyonu süper lig örneği. Kastamonu Education Journal, 28(2), 947-957. doi:10.24106/kefdergi.635944 


\section{Extended Abstract}

Introduction: The complexities and difficulties in human life cause individuals to face many problems. Overcoming problems can be achieved with appropriate solution skills. Human beings need problem solving skills in order to continue their both daily and social and professional lives effectively. Although solution is important for a problem, knowing what the problem is primarily plays an effective role in completing the process. The concept of problem has a broad meaning because it is evident that there are different problematics in every life pattern. In this respect, addressing and solving problems that vary from person to person and from profession to profession may differ from one another.

Individuals' achieving goals in their professional and social lives is related to problem solving skills as well as being related with how they use their ego states of Transactional Analysis (TA) theory in their problem solving skills and decision-making processes (Çam, 1995). TA Theory provides a highly understandable perspective in understanding and explaining people's thoughts, feelings and behaviours in many areas such as personality, development, interpersonal relations and psychotherapy (Akkoyun, 2011). As a personality theory, TA is a theory that helps us to understand humans' psychological structure by using the model of ego states and to understand how people exhibit their functionality-personality in terms of behaviour (Stewart and Joines, 2017). As a communication theory, TA can be used extensively as a method for analysing systems and relationships both in personal life and in the work environment (Stewart and Joines, 2017).

In line with all these, problem solving skills and TA ego situations are the two elements that are needed in many areas of life. They also have an important place in sports psychology. Increasing sporting performance and overcoming cognitive and psychological problems that prevent sporting performance are related with how individuals use their problem solving skills and TA ego states.

Based on these, the aim of the present study is to examine the relationship between problem solving skills and ego states of table tennis athletes in Turkish super league in terms of some variables.

Method: Descriptive relational screening method, which is one of the quantitative research methods, was used in the study. The population of the study consists of athletes in Turkish Table Tennis Federation Super League during the 2018-2019 season ( $n=$ 70). Total population sampling method was used in the study since all of the athletes in Turkish Table Tennis Super League were available and the number of athletes making up the population was limited. In the study, "The Ego States Scale", which was tested for validity, reliability and standardization, was used to find out the ego states of the athletes, while "Problem Solving Inventory", which was tested for validity and reliability, was used to find out their problem solving skills and "Personal Information Form" was used to obtain the athletes' demographic and sporting information. The differences between total scores of the athletes' ego states (Critical Parent (CP), Nurturing Parent (NP), Adult (A), Free Child (FC) and Adapted Child (AC)) according the variables of educational status, gender and being a national team athlete were analysed with One-way ANOVA and Tukey multiple comparison test. The correlation between the athletes' problem solving skills and their ego states was analysed with Pearson correlation coefficient. The results of the study were expressed in $n(\%)$, average and standard deviation and considered as significant at the level of $P<0,05$. All statistical analyses were made with SPSS $22.0 \mathrm{~V}$.

Results: According to the results of the study, statistically significant difference was found between the athletes' ego states, problem solving skills sub-dimensions and problem solving skills total scores in terms of their level of education, gender and being a national team athlete. Statistically significant difference was found between only " $C P$ ", " $N P$ ", " $A$ " ego states of the athletes in terms of the athletes' level of education. Statistically significant difference was found between only Adult and Adapted Child ego states of the athletes in terms of the athletes' gender distribution. Statistically significant difference was found between only Impulsive Style problem solving skills sub-dimension of the athletes in terms of the athletes' being national team player. In terms of the correlation between athletes' problem solving skills and ego states, a positive significant relationship was found between adult ego state and Impulsive Style, and between Free Child and Problem Solving Skills Total Score, Impulsive Style and Avoidant Style.

Discussion: It has been stated that individual athletes and athletes who do sports regularly have lower problem solving skills than team athletes and this situation may be related to the instructing side of team sports (Canan and Ataoğlu, 2010). However, it may not be right to keep the problem solving skills in a pure evaluation in terms of individual and team sports because each sports branch has different characteristic game and playing features. For this reason, it is necessary to approach table tenn is, which is an individual sport, in this respect. Table tennis is played much faster than other sports and the quick decision and the right move takes place in seconds and split seconds. For this reason, it can be thought that the characteristic feature of the game may be reflected in the problem solving skills of the athletes. Indeed, there is no doubt among researchers that there is an interaction between sports and personality (Allen et al., 2013). In addition, there are many studies in literature showing that different sports branches show parallelism with different personality traits (Yıldız, 2008; Allen et al., 2013; Erdoğan and Kocaekşi, 2015). According to the hypotheses of socialization and selectivity, sport affects personality and personality is not only effective in the sport branch, but also in the success of the individual in sport (cited from Bierhoff-Alfermann, 1986, ikizler and Karagözoğlu 1993: 94).

Conclusion: In conclusion, the relationship between " $A$ " and " $F C$ " ego states of table tennis athletes and "IS" and "AS" subdimensions can be seen as an effect of table tennis sport on athletes. However, it should be emphasized that it is an indicator of a negative situation in terms of theoretical basis. 


\section{Giriş}

Beşeri bir hayat akışı içerisindeki karmaşıklıklar ve zorluklar bireylerin birçok problem ile karşı karşıya gelebilmelerine sebep olmaktadır. Yaşanılan problemlerin veya sorunların üstesinden gelinebilmesi ise uygun çözüm becerileri ile sağlanabilir. İnsanlar gerek günlük yaşamlarını gerekse sosyal ve mesleki hayatlarını etkin bir şekilde sürdürebilmesi için problem çözme becerilerine intiyaç duymaktadır. Çözüm bir problem için her ne kadar önemli olsa da, öncelikli olarak problemin ne olduğunu bilmek sürecin tamamlanmasında etkili bir rol oynamaktadır. Problem kavramı geniş bir anlam içerir çünkü her yaşam örüntüsü içinde farklı sorunsalların olduğu aşikârdır. Bu bakımdan kişiden kişiye, meslekten mesleğe değişen sorunların ele alınması ve çözülmesi birbirlerinde farklıık içerebilir.

Bir durumun problem olarak algılanabilmesi için o durumun kişinin kendisi tarafından problem olarak görülmesi gerekir. Problem, temel olarak kişinin bir amaca ulaşması için çaba sarfettiği sürecin engellere maruz kalması ile oluşan bir güçlük çekme, karmaşıklık ve çatışma durumudur (Morgan, 1982). Problemler kişiden kişiye farklıık gösterebildiği gibi, aynı problemlerin çözümü de kişiden kişiye değişiklik gösterebilir. Bazıları amacına ulaşmada önünü çıkan engellerin üstesinden gelme konusunda başarılı olurken, bazıları başarısız veya etkisiz olması mümkündür (Öztürk ve diğ., 2016). Işte tam bu noktada problem çözme becerisi bireyler için oldukça önemlidir. Çünkü belirlenen hedefe ulaşılmasında karşılaşılan güçlüklerin ve engellerin üstesinde gelme bilişsel ve psikolojik beceri gerektirir (Oğuzkan, 1989).

Problem çözme becerisi içerisinde karar verme süreçleri de oldukça kritiktir. Çünkü problemin çözülmesi için karar verme aşamaları insan yaşamının tümünde etkili bir rol oynayabilir (Thornton, 1998). Birey, problemin çözümü esnasında duruma uygun yerinde verilen kararlar sayesinde problemi çözüme kavuşturma konusunda olumlu ve etkili olurken, hatalı verilmiş kararlarla da problemin üstesinde gelinmesini güçleştirmekte ve kişiyi yıpratıcı bir rol oynayabilmektedir (Yiğiter, 2012).

Bireylerin mesleki ve sosyal yaşantıları içerisinde hedeflerine ulaşabilmesi problem çözme becerisi ile ilgili oluğu kadar, bireylerin problem çözme becerileri ve karar verme süreçleri içinde Transaksiyonel Analiz (TA) kuramına ait ego durumlarını nasıl kullandığıyla da ilgisi vardır (Çam, 1995). TA Kuramı kişilik, gelişim, kişilerarası ilişkiler ve psikoterapi gibi birçok alanda insanların düşünce, duygu ve davranışlarının anlaşılmasında ve açıklanmasında oldukça anlaşılır bir bakış açısı sunmaktadır (Akkoyun, 2011). Bir kişilik kuramı olarak TA, insanların psikolojik yapısını ego durumları modelini kullanarak nasıl olduğunu, insanların işlevselliğini-kişiliklerini davranışsal olarak nasıl sergilediklerini anlamamıza yardımcı olan bir kuramdır (Stewart ve Joines, 2017). Bir iletişim kuramı olarak TA ise hem kişisel yaşamda hem de iş ortamında sistemlerin ve ilişkilerin analiz edilmesini sağlayan bir yöntem olarak çok geniş kapsamlı şekilde kullanılabilmektedir (Stewart ve Joines, 2017).

TA'da ego durumları modeli, yapısal ve fonksiyonel olarak iki ayrı modeli içerir. Yapısal model ego durumları içeriğiyle, fonksiyonel model ego ise bu içeriğin süreci ile ilgilidir. Kişiliği, Ebeveyn, Yetişkin ve Çocuk ego durumları olarak gösteren model, yapısal; kişiliği Koruyucu Ebeveyn (KE), Eleştirel Ebeveyn (EE), Yetişkin, Doğal Çocuk (DÇ) ve Uygulu Çocuk (UÇ) ego durumları olarak gösteren model ise fonksiyonel modeldir (Akkoyun, 2011).

EE ego durumu bireyde eleştiren, kusur bulan, istekçi, sınır koyan, ön yargılı, otoriter, gelenekleri sürdürmeye yönelik çaba sarfeden davranışlarla kendini gösterir. KE ego durumu ise destekleyici, koruyucu, sevecen, besleyici, şefkatli, affedici gibi davranışlarda gözlenir. DÇ ego durumu yaratıcılık, hayattan zevk alma, kendiliğindenlik, hareketlilik, neşeli ve canlı yaşantılarda görülür. UÇ ego durumu, davranış ve tutumlarda kurallara uyma, kendini sınırlama, çekingenlik, gerginlik gibi özellikler gösteren davranışlar olarak dışarıya yansımaktadır. EE, KE, DÇ ve UÇ ego durumlarının her biri hem olumlu hem de olumsuz özellikler göstermesi açısından ikiye ayrılmaktadır. "Olumlu yönü"; bireyin varlığını ve gelişmesini koruyan, destekleyen ve sürdüren; "olumsuz yönü" ise bireyin gelişmesini engelleyen, varlığını tehdit eden özellikler içeren davranış örüntüleri şeklinde tanımlanmaktadır. Y ego durumu ise, bireyde gerçekliğe uygun davranış ve tutumlar, sistemli olma, planlı bir şekilde mantıklı karar verme gibi özellikleriyle kendini gösterir. Bu davranış örüntüleri bireyde bir bütünlük içinde yer alır. Birey davranışta bulunurken içinde bulunduğu duruma göre, daha çok gelişmiş olan ego durumundan tepkide bulunma eğilimindedir (Çam, 1995).

Etkin problem çözme; problemin doğru tanımlanması, ilgili bilgilerin toplanması, çözüm seçeneklerinin belirlenmesi ve en uygun olanı seçerek uygulamaktır (Kuzgun, 1992'den akt., Çam, 1994). TA kuramına göre bu davranışların kaynağı, Y ego durumu, problem çözme enerjisi ise DÇ ego durumundadır; nesnel verileri işleme gücü de Y ego durumunun işlevidir (Schmid, 1986'den akt., Çam, 1995).

Yüksek problem çözme algısına sahip olanlar, düşük olanlara göre Y ve KE ego durumlarında anlamlı olarak daha yüksek puan ortalamasına sahiptirler. Düşük problem çözme becerisi algısına sahip olanlar ise, yüksek olanlara göre 
UÇ, DÇ ve EE ego durumlarında daha yüksek puan ortalaması elde etmişlerdir, Böylece yüksek problem çözme becerisi algısına sahip olanların düşük olanlara göre $\mathrm{Y}$ ve KE; düşük problem çözme becerisi algısı olanlar ise yüksek olanlara göre UÇ, DÇ ve EE ego durumlarına daha yüksek düzeyde sahip oldukları söylenebilir (Çam, 1995).

Sonuçta problem çözme becerisi daha çok $Y$ ve KE durumunun kullanılmasıyla olumlu; UÇ, EE ve DÇ ego durumlarıyla olumsuz ilişkisinin olduğu söylenebilir. Böylece bulgular, TA kuramına göre bireylerin problem çözme gücünün Yetişkin ego durumunun işlevi olduğu yönündeki görüşü desteklemektedir.

Tüm bunların doğrultusunda problem çözme becerisi ve TA ego durumları hayatın birçok alanında intiyaç duyulan iki unsur olmasının yanında spor psikolojisi içerisinde de önemli bir yeri vardır. Sportif performansın artırılması ve sportif performansa engel olan bilişsel ve psikolojik problemlerin üstesinden gelinmesi, bireylerin problem çözme becerilerini ve TA ego durumlarının nasıl kullandığı ile ilgilidir.

Buradan hareketle bu çalışmanın amacı, Türkiye süper liginde mücadele eden masa tenisi sporcularının problem çözme becerileri ile ego durumları arasındaki ilişkiyi bazı değişkeler açııında incelemektir.

\section{Yöntem}

\section{Araştırmanın Modeli}

Bazı değişkenler açısından sporcuların problem çözme becerileri ile ego durumları arasındaki ilişkinin incelenmesi için araştırmada nicel araştırma yöntemlerinden betimsel nitelikte ilişkisel tarama yöntemi kullanılmıştır. Tarama modelleri geçmişte ya da halen var olan bir durumu var olduğu şekli ile betimlemeyi amaç edinen araştırmalar için uygun bir modeldir (Karasar, 2006). iliş̧kisel tarama modeli, iki ve daha çok değişken arasındaki birlikte değişimin varlı̆ıını veya derecesini belirlemeyi amaçlayan araştırma modelidir (Karasar, 2006).

\section{Araştırmanın Evreni ve Örneklemi}

Araştırma evrenini 2018-2019 sezonunda Türkiye Masa Tenisi Federasyonu Süper Ligi'nde mücadele eden sporculardan ( $n=70$ ) oluşmaktadır. Türkiye Masa Tenisi Süper Ligi'nde mücadele eden tüm sporcular ulaşılabilir ve evreni oluşturan sporcu sayısının sınırlı olması (az) nedeni ile çalışmada tam sayım tekniği kullanılmıştır.

\section{Veri Toplama Aracı}

Araştırmada sporcuların ego durumlarını belirlemek için geçerlilik, güvenirlilik ve standardizasyon çalışmaları yapılmış "Ego Durumları Ölçeği (EDÖ)", Problem çözme becerilerini belirlemek için geçerlilik ve güvenirlilik çalışmaları yapılmış "Problem Çözme Envanteri" ve onların demografik ve sporcu özelliklerine ait bilgileri elde etmek için "Kişisel Bilgi Formu" kullanılmıştır.

\section{Ego Durumları Ölçeği (EDÖ)}

Arı (1989) ölçeğin güvenirlilik çalışmasını, uzman değerlendirmeleri arasındaki tutarlılık ve Testin Tekrarı tekniği olmak üzere iki farklı yöntemle yapmıştır. Ego Durumları Ölçeği'nin geliştirme çalışmaları içinde hakemlerin her ego durumu için verdikleri puanlar arasındaki korelasyon Sınıf İçi Korelasyon tekniği ile hesaplanmıştır. Bu hesaplamalar sonucu hakem değerlendirmeleri arasında Eleştirel Ebeveyn Ego Durumu (EE) için $r=.95$; Koruyucu EbeveynEgo Durumu (KE) için $r=.93$; Yetişkin Ego Durumu (Y) için $r=.96$; Doğal Çocuk Ego Durumu (DÇ) için $r=.89$ ve Uygulu Çocuk Ego Durumu (UÇ) için $r=.91$ tutarlılık katsayıları elde edilmiştir. EDÖ’nin güvenirliliği ile ilgili ikinci çalışma Testin Aralıklı Tekrarı tekniği ile yapıımıştır. EDÖ, Yüksek Öğretim Kurumu tarafından düzenlenen dil kursuna katılan 32 öğretim elamanına (20 erkek 12 kadın) 34 gün ara ile iki kez verilmiştir. İki uygulamadan elde edilen ego durumları arasında EE için $r=.78$; KE için $r=.83$; $Y$ için $r=81$; DÇ için $r=.77$ ve UÇ için $r=.74$ güvenirlik katsayıları elde edilmiştir. EDÖ'nin güvenirlik katsayııının Testin Tekrarı ile hesaplanmasında dikkati çeken önemli nokta, deneklerin iki uygulamada eşit sayıda sıfat işaretleseler bile bu sıfatların farklı sıfatlar olabileceği gerçeği olmuştur. Bu durumda her iki uygulamada işaretlenen sıfatlardan hareket edilerek tutarlılı̆ın belirlenmesine çalışılmıştır. Her bireyin iki uygulamada işaretlediği ortak sıfat sayısı iki uygulamada işaretlediği toplam sıfat sayısına bölünerek tutarlılık katsayısı bulunmuştur. İki uygulama arasındaki tutarlığın ortak varyans olduğu ve bunun da iki uygulama arasındaki korelasyonun karesine $(\mathrm{r} 2)$ eşit olduğu göz önüne alınarak tutarlılık katsayısının karekökü alınarak tahmini bir güvenirlik katsayısı bulunmuştur. Bu yöntemle iki uygulama arasında $r=.87^{\prime}$ lik tahmini güvenirlik katsayısı elde edilmiştir. Arı (1989), Ego Durumları Ölçeği geçerlik çalışmasında mantıksal ve istatiksel yaklaşım izlenmiştir. Mantıksal geçerlilikle çalışmada uzman görüşüne başvurulmuştur. TA konusunda doktora düzeyinde ders vermiş ya da çalışma yapmış sekiz uzman ölçeği oluşturacak sıfatların seçiminde görünüş ve kapsam geçerliği bakımından yardımcı olmuşlardır. Ayrıca ölçeği oluşturan sıfatların puanlamasında yararlanılan altı hakemin değerlendirmeleri arasındaki yüksek tutarlıık, EDÖ’nin mantıksal geçerliliği 
için önemli bir kanıt sayılmıştır. Bunlara ek olarak EDÖ’nin kapsam geçerliliği ile ilgili olarak Williams ve Williams (1980), James ve Jongeward'in (1984) çalışmalarından da yararlanılmıştır. EDÖ'nin yapı geçerliliğini kontrol etmek amacıyla ölçeğin beş ego durumu arasında ilişki; TA'da ego durumunun teorik tanımlarıyla karşılaştırılmıştır. EDÖ’nin alt ölçekleri arasındaki ilişkinin TA'daki ego durumlarının teorik tanımlarına uygun olduğu gözlenmiştir. EDÖ içinde her sıfatın her bir ego durumunu içine " 0 " ile " 4 " arasında değişen standart beş ayrı değeri vardır. Bu değerler daha önce de sözü edildiği gibi 6 kişilik bir hakem grubunun bir sıfata her ego durumu için verdiklerin puanların ortalamasıdır. Katılımcıların işaretlediği her sıfat, beş ego durumu için hakemlerden elde edilen sıfat listesindeki puanlara bakılarak puanlanır. Puanlama işleminden sonra her ego durumundaki puanlar toplanarak beş ayrı toplam puan elde edilir. Sonra bu puanlar o ego durumu için ölçekten alınabilecek en yüksek puana bölünür. Bu işlem diğer dört ego durumu için de tekrarlanır. Bu işlemden elde edilen beş ego durumun puanı toplanır ve her puanın bu toplam puana bölünmesi ile her ego durumunun bir bütün içindeki oranları gösteren ego durumları puanları elde edilir (Arı, 1989). Yukarıdaki işlemler aşağıdaki gibidir.

İşlem 1.

1.1. $X E E /[O ̈ A \times E E]=K 1$

1.2. XKE / [ÖA $\times K E]=K 2$

1.3. $X Y /[O ̈ A X Y]=K 3$

1.4. $X D C ̧ /[O ̈ A \times D C ̧]=K 4$

1.5. XUÇ/ [ÖA $\times \cup C ̧]=K 5$

İşlem 2. $K 1+K 2+K 3+K 4+K 5=M$

\section{İşlem 3.}

1.6. $K 1 / M=E E P$

1.7. $K 2 / M=K E P$

1.8. $K 3 / M=Y P$

1.9. $K 4 / M=D C ̧ P$

1.10. $K 5 / M=U C ̧ P$

\section{Problem Çözme Envanteri}

Orijinal adı Problem Solving Inventory, Form-A (PSI-A) olan Problem Çözme Envanteri (PÇE), Heppner ve Petersen (1982) tarafından çeşitli araştırmalar sonucu ortaya çıkan "genel yönelim", "problemin tanımı", "alternatif üretme", "karar verme" ve "değerlendirme" gibi problem çözme aşamaları göz önünde bulundurularak, kişinin problemlerini çözebilme yeterliliği konusunda kendisini nasıl algıladığının yanı sıra, problem çözme yönteminin boyutlarını da belirlemek amacıyla geliştirilmiştir (Savaşır ve Şahin, 1997). Ölçeğin Türkçe uyarlama çalışmaları çerçevesinde çeviri çalışmaları, sırasıyla Akkoyun ve Öztan (1988'de akt., Ferah, 2000), Taylan (1990), Şahin, Şahin ve P.P. Heppner (1993); geçerlilik güvenirlilik çalışmaları ise Taylan (1990), Şahin, Şahin ve P.P. Heppner (1993) ve Çam (1995) tarafından yapılmıştır.

\section{Şahin ve Heppner (1993), tarafından yapılan faktör analizi sonucunda ölçeğin;}

\section{Aceleci Yaklaşım (AY): 13, 14, 15, 17, 21, 25, 26, 30 ve 32. maddeler, $\alpha=0.78$,}

Birey, sorunu çözebilmek adına onun üzerinden hiç düşünmeden aklına ilk gelen yolu izler. Sorunun olası çözüm yollarını düşünürken çok fazla seçenek üretmeden ve değerlendirmeden sorunu çözmeye çalışır. Birey, sorunu çözme çabası içine girdiğinde gereksiz ayrıntılar içinde boğulduğunu, olayın daha da karmaşık hale geldiği hissini yaşar. Kişi, oluşan bir sorunun kendisi dışında etmenlerin genellikle dikkate almaz. Birey sorunun etkisinde kaldığında duygusal olarak bir çöküş yaşar ve sorunla başa çıkma konusunda birçok seçeneği dikkate almaz. Bu durumların sonucunda kişi, ani kararlar verir ve sonra bu durumdan pişmanlık yaşar (Heppner ve Petersen, 1982).

\section{Düşünen Yaklaşım (DY): 18, 20, 31, 33 ve 35. maddeler, $\alpha=0.76$,}

Birey, karar verme sürecinde her durumu göz önünde tutar, ölçer, tartar, karşılaştırma yapar ve tüm bunlarında sonrasında sorunun çözümü için ne yapacağına karar verir. Birey uygulacağı yöntemin nasıl bir sonuç vereceği ile ilgili öngürülerde bulunur. Birey, bu süreçlerden sonra bir karar verir ve problemin veya sorunun çözülmesi ile ilgili ortaya çıkan sonuç/sonuçlar kişinin öngördüğü sonuç/sonuçlar ile paralellik gösterir (Heppner ve Petersen, 1982).

\section{Kaçıngan Yaklaşım (KY): 1, 2, 3 ve 4. maddeler, $\alpha=0.74$,}

Problemin çözümü adına verdiği uğraş başarısızlık ile sonuçlanması durumunda, birey niçin başarısız olduğu konusu üzerine düşünmez ve bunu araştırmaz. Sorunun çözülmesinin zor olduğunu düşündüğünde, sorunun çözümü ile ilgili ne yapılması gerektiği ile ilgili bilgileri uzun uzadıya düşünmez. Bireyin, sorunun çözümü adına verdiği uğraşlar boşa çıkması durumunda, birey sorunu çözebileceği konusunda şüpheye düşür ve karamsar bir tavır takınır (Heppner ve Petersen, 1982). 
4. Değerlendirici Yaklaşım (DRY): 6, 7 ve 8. maddeler, $\alpha=0.69$,

Sorunu çözümü adına tüm yol ve yöntemleri düşünür, kullandığı yol ve yöntemlerden edindiği sonuç ile beklediği sonuç arasında bir karşılaştırma yapar. Birey, bir sorunla karşılaştığında nasıl bir hissiyat içinde olduğunu anlamaya çalışır (Heppner ve Petersen, 1982).

5. Kendine Güvenli Yaklaşım (KGY): 5, 11, 23, 24, 27, 28 ve 34. maddeler, $\alpha=0.64$,

Birey bu yaklaşım ile sorunları çözebilme adına yaratıcı ve etkili çözümler üretilebildiğini ifade eder. Karşılaştı̆̆ı sorunların çoğu, çözebileceğinden daha zor ve karmaşık olduğunu, fakat yeterince zaman olduğunda ve çaba gösterdiğinde karşılaşılan sorunların çoğunu çözebileceğine inanır. Sorunları çözebilme yeteneğine güvenir ve sorunu çözebilme konusunda kendine oldukça emindir. Birey, çözüm seçeneklerini karşılaştırırken ve karar verirken kullandığı sistematik bir yöntem kullanır (Heppner ve Petersen, 1982).

6. Planlı Yaklaşım (PY): 10, 12, 16 ve 19. maddeler, $\alpha=0.59$, olmak üzere 6 faktörden oluştuğu belirtilmektedir.

Birey, ilk aşamada sorunun ne olduğunu fark edemese de, karşılaşılan sorunları çözme yeteneği sahiptir. Birey genellikle kendisi ile ilgili kararları verme konusunda doğru adımları atabilir ve bu durumdan hoşnut olur. Bir sorun ile karşılaşıldığında, birey öncellikle o sorun üzerinde düşünür daha sonra başka bir konuya geçiş sağlar. Birey, bir sorunu çözmek adına plan yaparken, o planı yürütebileceğine güvenir (Heppner ve Petersen, 1982). Verilen cevaplara 1 ile 6 arasında değişen puanlar verilir. Puanlamada 9, 22 ve 29. maddeler puanlama dışı tutulur. Puanlama 32 madde üzerinden yapılır. 1, 2, 3, 4, 11, 13, 14, 15, 17, 21, 25, 26, 30 ve 34. maddeler ters olarak puanlanan maddelerdir. Envanterden alınabilecek puan ranjı, 32-192 arasıdır. Ölçekten alınan toplam puanların yüksekliği, bireyin problem çözme becerileri konusunda kendini yetersiz olarak algıladığını gösterir. Ölçekten alınan toplam puanların azalmasında ise kişinin problem çözme beceri algısının olumlu olduğu kabul edilir. Alt ölçeklerin puanlanmasında da olumlu-istendik olarak nitelendirilebilecek problem çözme yaklaşım biçimlerini ölçen alt ölçeklerden (düşünen yaklaşım, kendine güvenli yaklaşım, değerlendirici yaklaşım, planlı yaklaşım) alınan puanlar azaldıkça ilgili yaklaşım biçimlerinin daha fazla kullanıldığı değerlendirilirken; olumsuz-etkisiz olarak nitelendirilebilecek problem çözme yaklaşım biçimlerini ölçen alt ölçeklerden (aceleci yaklaşım ve kaçıngan yaklaşım) alınan puanlar azaldıkça ilgili yaklaşım biçimlerinin daha az kullanıldığı düşünülür (Ferah, 2000). Ölçek masa tenisi sporcularının problem çözme becerilerini ölçebilmeyi amaçlamaktadır. İç tutarlık (Cronbach Alpha) güvenilirlik katsayısı 0,72 olarak bulunmuştur.

\section{Kişisel Bilgi Formu}

Araştırmanın örneklemini oluşturan masa tenisi sporcularının demografik ve sporcu özelliklerini tespit etmek amacı ile araştırmacılar tarafından oluşturulan kişisel bilgi formu kullanılmıştır. Bu formda eğitim, cinsiyet, yerleşim yeri, kullanılan el, oyun stili ve milli sporcu olup olmadığı gibi bilgileri toplamaya yönelik sorulara yer verilmiştir.

\section{Verilerin Toplanması}

Araştırmada verilerin toplanması ve ölçeklerin uygulanmasında öncelikli olarak Ondokuz Mayıs Üniversitesi'nden 22/02/2019 tarihinde 2019/34 karar sayılı, Sosyal ve Beşerî Bilimler Etik Kurulu'ndan resmi izinler alınmıştır. İzin alındıktan sonra Türkiye Masa Tenisi Federasyonu Süper Ligi'nde mücadele eden sporcular ve antrenörleri ile ön görüşmeler yapılmış ve araştırmacı, ilgili kişilere kendini tanıtarak araştırmanın içeriği hakkında; araştırmanın amacı, araştırmadan hangi ölçeğin kullanılacağı, uygulama şekli, süresi, araştırmanın yararı, gizlilik sınırları, başladıktan sona vazgeçme hakları gibi birtakım bilgiler aktarmıştır. Bu süreçten sonra sporculara "Ego Durumları Ölçeği", "Problem Çözme Envanteri" ve "Kişisel Bilgi Formu" verilerek doldurmaları istenilmiştir. Veriler Türkiye Masa Tenisi Federasyonu tarafından Antalya'da düzenlenen Süper Lig 3. Etap müsabakalarında toplanmıştır. Uygulama, sporculara toplu halde ancak birbirinden etkilenmeyecekleri bir oturma düzeninde oturtturularak süreç tamamlanmıştır.

\section{Verilerin Analizi}

Araştırma da elde edilen verilere uygulanacak olan testlerin seçimi öncesinde hata terimlerinin normal dağılım gösterip göstermediği kontrol etmek amacı ile Shapiro-Wilk normallik testi uygulanmıştır $(P>0,05)$. Araştırmaya katılan sporcuların eğitimi, geliri, mevcut durumuna göre sporcuların ego durumlarına ait (Eleştirel Ebeveyn, Koruyucu Ebeveyn, Yetişkin, Doğal Çocuk ve Uygulu Çocuk) toplam puanlar arasındaki farklılıklar Tek Yönlü Varyans Analizi (Oneway ANOVA) ve Tukey çoklu karşılaştırma testi ile analiz edilmiştir. Sporcuların eğitim düzeyi, cinsiyeti, kullandığı el, oyun stili ve milli sporcu olup olmadığına göre onların ego durumlarına ait toplam puanları arasındaki farkın istatiksel olarak anlamlı olup olmadığı belirlemek için T-test kullanılmıştır. Sporcuların problem çözme becerileri ile onların ego durumları arasındaki ilişki ise Pearson korelasyon katsayısı ile incelenmiştir. Araştırma bulguları $n(\%)$, ortalama ve standart sapma olarak ifade edilmiş olup, $\mathrm{P}<0,05$ önem seviyesinde anlamlı kabul edilmiştir. Tüm istatistiksel hesaplamalar SPSS $22.0 \mathrm{~V}$. istatistik paket programda yapılmıştır. 


\section{Bulgular}

Türkiye Masa Tenisi Federasyonu 2018-2019 sezonu içinde Süper Lig 3. Etap müsabakalarında mücadele eden ve araştırmaya gönüllü olarak katılan sporcuların eğitim, cinsiyet ve milli sporcu olup olmadığı göre Ego Durumları, Problem Çözme Becerisi Alt Boyutları ve Problem Çözme Becerileri Toplam Puanlarına ait tanımlayıcı istatistikler tablolar halinde verilmiştir. Tablolarda sadece istatistiki olarak anlamlı bir farklılık içeren Ego Durumları, Problem Çözme Becerisi Alt Boyutları ve Problem Çözme Becerileri Toplam Puanlarına yer verişmiştir. İstatistiki olarak anlamlı bir farklılık içermeyen Ego Durumları, Problem Çözme Becerisi Alt Boyutları ve Problem Çözme Becerileri Toplam Puanlarına yer verilmemiştir.

Tablo 1. Sporcuların Eğitim Durumlarına Göre Ego Durumları, Problem Çözme Becerisi Alt Boyutları ve Toplam Puanları

\begin{tabular}{cccccc}
\hline & Eğitim Durumu & $\mathbf{n}$ & Ortalama & Std. Sapma & $\mathbf{p}$ \\
\hline \multirow{3}{*}{ Eleştirel Ebeveyn } & Ortaokul & 5 & 0,140 & 0,041 & \\
& Lise & 41 & 0,203 & 0,041 & $\mathbf{0 , 0 1 0}$ \\
& Lisans & 22 & 0,184 & 0,040 & \\
\hline \multirow{3}{*}{ Yüksek lisans } & 2 & 0,195 & 0,033 & \\
& Ortaokul & 5 & 0,242 & 0,023 & \\
& Lise & 41 & 0,202 & 0,025 & $\mathbf{0 , 0 0 5}$ \\
& Lisans & 22 & 0,218 & 0,028 & \\
\hline Yüksek lisans & 2 & 0,204 & 0,023 & \\
& Ortaokul & 5 & 0,218 & 0,006 & \\
& Lise & 41 & 0,211 & 0,017 & $\mathbf{0 , 4 0 4}$ \\
& Lisans & 22 & 0,217 & 0,018 & \\
\hline
\end{tabular}

Yapılan araştırmada sporcuların eğitim düzeyi dağılımına göre Ego Durumları, Problem Çözme Becerisi Alt Boyutları ve Toplam Puanları arasından sadece EE, KE, Y ego durumları arasında istatistiki olarak anlamlı bir farklılık tespit edilmiştir $(P<0,05$; Tablo 1$)$.

Tablo 2. Sporcuların Cinsiyetine Göre Ego Durumları, Problem Çözme Becerisi Alt Boyutları ve Toplam Puanları

\begin{tabular}{cccccc}
\hline & Cinsiyet & $\mathbf{n}$ & Ortalama & Std. Sapma & $\mathbf{p}$ \\
\hline \multirow{2}{*}{ Yetişkin } & Kadın & 43 & 0,208 & 0,017 & \multirow{2}{*}{$\mathbf{0 , 0 0 3}$} \\
& Erkek & 27 & 0,220 & 0,015 & \\
\hline \multirow{2}{*}{ Uygulu Çocuk } & Kadın & 43 & 0,200 & 0,015 & \multirow{2}{*}{$\mathbf{0 , 0 4 2}$} \\
& Erkek & 27 & 0,190 & 0,024 & \\
\hline
\end{tabular}

Yapılan araştırmada sporcuların cinsiyet dağılımına göre Ego Durumları, Problem Çözme Becerisi Alt Boyutları ve Toplam Puanları arasından sadece Yetişkin ve Uygulu Çocuk ego durumları arasında istatistiki olarak anlamlı bir farklılık tespit edilmiştir $(P<0,05$; Tablo 5$)$.

Tablo 3. Sporcuların Milli Sporcu Olup Olmadığına Göre Ego Durumları, Problem Çözme Becerisi Alt Boyutları ve Toplam Puanları

\begin{tabular}{cccccc}
\hline & Milli & $\mathbf{n}$ & Ortalama & Std. Sapma & $\mathbf{p}$ \\
\hline Sporcu & Evet & 36 & 29,417 & 9,075 & \multirow{0}{*}{$\mathbf{0 1 1}$} \\
Yaklaşım & Hayıı & 34 & 35,059 & 8,876 & \\
\hline
\end{tabular}

Yapılan araştırmada sporcuların milli sporcu olup olmadığına göre Ego Durumları, Problem Çözme Becerisi Alt Boyutları ve Toplam Puanları arasından sadece Aceleci Yaklaşım Problem Çözme Becerisi Alt Boyutu arasında istatistiki olarak anlamlı bir farklılık tespit edilmiştir $(P<0,05$; Tablo 7). 
Tablo 4. Sporcuların Ego Durumları ile Problem Çözme Becerisi Alt Boyutları ve Toplam Puanları Arasındaki Korelasyon

\begin{tabular}{llccc}
\hline & & PÇET & AY & KY \\
\hline Yetişkin Ego & $\mathrm{R}$ & 0,201 & $0,298^{*}$ & 0,221 \\
Durumu & $\mathrm{p}$ & 0,095 & $\mathbf{0 , 0 1 2}$ & 0,066 \\
\hline Doğal Çocuk & $\mathrm{R}$ & $-0,241^{*}$ & $-0,250^{*}$ & $-0,254^{*}$ \\
Ego Durumu & $\mathrm{p}$ & $\mathbf{0 , 0 4 4}$ & $\mathbf{0 , 0 3 7}$ & $\mathbf{0 , 0 3 4}$ \\
\hline
\end{tabular}

Yapılan araştırmada sporcuların problem çözme becerileri ile ego durumları arasındaki korelasyon, Yetişkin ego durumu ile Aceleci Yaklaşım arasında pozitif anlamlı bir ilişki, Doğal Çocuk ile Problem Çözme Becerileri Toplam Puanı, Aceleci Yaklaşım, Kaçıngan Yaklaşım arasında pozitif anlamlı bir ilişki olduğu tespit edilmiştir $(P<0,05$; Tablo 4).

\section{Tartışma ve Sonuç}

Sporcuların eğitim durumlarına göre ego durumları, problem çözme becerisi alt boyutları ve toplam puanları sadece EE, KE, Y ego durumları arasında istatistiki olarak anlamlı bir farklılık tespit edilmiştir ( $P>0.05 ;$ Tablo 1). EE ego durumunda en yüksek ortalama puana sahip lise öğrencisi veya mezunu olan sporcuların olduğu, KE ve $Y$ ego durumlarında ise ortaokul mezunu sporcuların en yüksek ortalama puana sahip olduğu görülmüştür. Atasoy (2019), genç amatör futbolcular üzerinde yaptığı çalışmada, lise mezunu ve üniversite öğrencisi futbolcuların Yetişkin ego durumları, ortaokul mezunu futbolcuların Yetişkin ego durumlarından daha yüksek olduğunu, futbolcuların eğitim durumu yükseldikçe $Y$ ego durumu puanlarının yükseldiği, eğitim düzeyi düştükçe, EE ego durumu puanları yükseldiği tespit etmiştir. Gülşen (2018), futbolcuların öğrenim durumları ile problem çözme becerileri arasındaki ilişkiyi incelenmiş, üniversite ve lise mezunu sporcuların problem çözme becerileri, ortaokul mezunu sporculara göre daha iyi düzeyde olduğunu tespit etmiştir. Buna karşın, Akın (2015) profesyonel futbolcular üzerinde yaptığı araştırmada, futbolcuların ego durumları ile eğitim düzeyleri arasında istatiksel anlamlı bir farklılığa rastlamamıştır.

Sporcuların cinsiyetine göre ego durumları, problem çözme becerisi alt boyutları ve toplam puanları incelendiğinde Problem Çözme Becerisi Alt Boyutları ve Toplam Puanları arasından sadece Yetişkin ve Uygulu Çocuk ego durumları arasında istatistiki olarak anlamlı bir farklılık tespit edilmiştir ( $P<0,05$; Tablo 5). İnce ve Şen (2006), bayan sporcuların problem çözme beceri ortalamalarının, erkek sporcuların ortalamalarından daha iyi olduğu saptamıştır. Bu anlamlı farklılığın antrenman ve müsabakalara bağlı deneyimleri ile ilgisi olabileceğini ifade etmişlerdir. Pulur ve ark. (2012) farklı branşlarda cinsiyete göre problem çözme becerilerinde farklılıklar olduğunu, bu farklılığın spor branşlarının bireysel oluşundan, sporcuların bireysel özelliklerinden veya erkek ve kızlara toplumda biçilen rollerden kaynaklandığı ifade etmişlerdir. Öztürk ve diğ., (2016), judocular üzerinde yaptığı çalışmada sporcuların problem çözme becerileri ile cinsiyet değişkeni üzerinde anlamlı bir farklılığın oluştuğunu tespit etmişlerdir. Erkek judocuların problem çözme becerilerine ait puan ortalamaları, kız judocularına oranla daha yüksek olduğunu, bu durumun kız judocuların erkek judocularına oranla olaylara ve karşılaştıkları problemlere karşı duygusal davranmaları, yapılan spor branşı gereği mücadeleye dayalı ve fiziksel sınırları zorlayan bir spor olmasından dolayı erkek judocuların kız judoculara oranla problem çözme becerilerinin yüksek olabileceğini ifade etmiştir. Demircan (2015), Problem çözme becerilerinin cinsiyet değişkeni ele almış ve kadın öğretmenlerin, erkek öğretmenlere oranla problem çözmede aceleci yaklaşımı kullanma düzeyi daha yüksek olduğunu bulmuş ve kadın öğretmenlerin bir problem ile karşılaştıklarında sonuç odaklı olaylara yaklaştıkları, erkek öğretmenlerin ise daha süreç odaklı olaylara yaklaştıkları şeklinde yorumlamıştır.

Sporcuların milli sporcu olup olmadığına göre Ego Durumları, Problem Çözme Becerisi Alt Boyutları ve Toplam Puanları arasından sadece AY Problem Becerisi Alt Boyutu arasında istatistiki olarak anlamlı bir farklılık tespit edilmiştir $(P<0,05 ;$ Tablo 7). Milli sporcuların milli olmayan sporculara göre daha yüksek AY problem çözme becerisi ortalama puana sahip olduğu tespit edilmiştir. AY problem çözme becerisi alt boyutuna göre birey bir sorun ile karşılaştığında ve onu çözmede konusunda etkili olmadığında daha duygusal bir çöküş yaşayabileceği, sorunla başa çıkma konusunda birçok seçeneği dikkate alamayacağı ve bu durumların sonucunda kişi, ani kararlar verip ve sonra bu durumdan pişmanlık yaşayabileceği ifade edilmiştir (Heppner ve Petersen, 1982). Bu bakımdan milli olmayan sporcuların milli olan sporculara göre bu durum veya durumları yaşamaları daha sık görülebilir. Buna karşın Öztürk ve diğ., (2016) yaptıkları araştırmada, judocuların milli sporcu olma durumuna göre problem çözme becerilerinde anlamlı bir farklılık bulamamıştır.

Sporcuların ego durumları ile problem çözme becerisi alt boyutları ve toplam puanları arasındaki korelasyona bakıldığında, Yetişkin ego durumu ile Aceleci Yaklaşım arasında pozitif anlamlı bir ilişki, Doğal Çocuk ego durumu ile Problem Çözme Becerileri Toplam Puanı, Aceleci Yaklaşım ve Kaçıngan Yaklaşım arasında pozitif anlamlı bir ilişki olduğu tespit edilmiştir ( $P<0,05$; Tablo 4). Etkin problem çözme; problemin doğru tanımlanması, ilgili bilgilerin toplanması, 
çözüm seçeneklerinin belirlenmesi ve en uygun olanı seçerek uygulamaktır (Kuzgun, 1992'den akt., Çam, 1995). TA kuramına göre bu davranışların kaynağı, $Y$ ego durumudur. Kurama göre, problem çözme enerjisi $D C ̧$ ego durumundadır; nesnel verileri işleme gücü de Y ego durumunun işlevidir (Schmid, 1986'den akt., Çam, 1995). Yüksek problem çözme algısına sahip olanlar, düşük olanlara göre Y ve KE ego durumlarında anlamlı olarak daha yüksek puan ortalamasına sahiptirler. Düşük problem çözme becerisi algısına sahip olanlar ise, yüksek olanlara göre UÇ, $D C ̧$ ve $E E$ ego durumlarında daha yüksek puan ortalaması sahiptirler (Çam, 1995). Elde edilen bulgularda, DÇ ego durumu ile problem çözme becerisi toplam puanı arasında pozitif anlamlı bir ilişki içinde olması( $P>0.05$; Tablo 4), Çam'ın (1995) problem çözme enerjisinin DÇ ego durumu ile oluşabileceği ifade ile paralellik göstermektedir. DÇ ego durumu, kişiliğin, yaratıcı ve yaşamı güzelleştirici parçası olduğu, kişinin sevecen ve içten geldiği gibi davranmasında rol oynayan, duyarlı, yaratıcı, özgür ve meraklı bir yapıya geçmesini sağlayan, bu nedenle etkileştirilmesinin önemli olduğu ifade edilmiştir (Arı, 1989; Solomon, 2003). DÇ ego durumuna sahip olan sporcuların, "problem çözme becerisi toplam puanları" dışında, "Aceleci Yaklaşım" (AY) ve "Kaçıngan Yaklaşım" (KY) alt boyutları arasında da pozitif anlamlı bir ilişkinin olduğu saptanmıştır. AY, bireyin karşılaşı̆̆ı̆ı problemlerin üzerinde yoğunlaşmadan sorunu çözmeye çalışır. Sorunu çözme çabası içerisine girdiğinde gereksiz ayrıntılara girerek olayın daha karmaşık hale geldiği hissine kapılır ve sorunun etkisinde kalarak duygusal bir çöküş yaşar. Bu durumların sonucunda kişi, ani kararlar verir ve sonra bu durumdan pişmanlık yaşar (Heppner ve Petersen, 1982). KY alt boyutunda, bireyin sorunun çözümü adı verdiği çaba başarısızlıkla sonuçlanması durumunda, niçin başarısız olduğu konusu üzerine düşünmez ve bunu araştırmaz. Bireyin, sorunun çözümü adına verdiği uğraşlar başarısızlıkla sonuçlanması durumunda, birey sorunu çözebileceği konusunda şüpheye düşür ve karamsar bir tavır takınır (Heppner ve Petersen, 1982).

DÇ ego durumu başkaldırı ya da vurdumduymazık gibi özerk davranışlarla desteklenebilir. En mantıkı sonuç ve sonuçları bulmak yerine kişinin kendisine en çok haz sağlayacak seçeneği belirlemek amacıyla kullanılır (Berne, 2015). işte bu nedenle $D C ̧$ ego durumu, problem çözmede bir enerji kaynağı olsa da, problemin çözümünde verilerin işleme gücü de $Y$ ego durumunun işlevidir. Çünkü Yetişkin ego durumu bireyde problem çözümlerine yönelik nesnel yaşantılar barındırır. Y ego durumu tüm gerçeği test etme ve problem çözme stratejileri kendinde depolar (Akkoyun, 2011), Çocuk ve Ebeveyn ego durumları arasında tarafsı bir değerlendirme yaparak düzen sağlar (Berne, 2015). "Ebeveyn" verilerinin günün koşullarına göre geçerlilik durumunu kontrol ederken, "Çocuk" verilerinde yer alan duyguların hangilerinin ifade edilmesinin güvenli olduğunu değerlendirir (Harris, 2018). Mantık ve nedene göre davranır ve heyecanlara kapılmadığından gerçeklerin en iyi değerlendiricidir (Baştuğ, 1993) "Yetişkin", öngörülerde bulunma ve kararlar vermek için verileri bir araya toplayıp işleme tabi tutan kişiliğin bir organıdır, bir bilgisayar gibi çalışır (Baştuğ, 1993). Fakat bilgisayardan farklı olarak her zaman çalışmaya hazır haldedir. Dünyadaki bilgileri toplamak ve verileri işlemek üzere bağımsız olarak çalışır. Ancak kendi kendine harekete geçemez, diğer ego durumlarının uyarısıyla harekete geçer (Akkoyun, 2011). Bir bilgisayara benzetilen Yetişkin ego durumlarının bozulması ya da bilinçsiz olması bireyin diğer insanlarla sağlıksız ilişkiler kurmasına neden olabilmektedir. Yetişkin ego durumunun bozulması ya da bilinçsiz olması Ebeveyn ve Çocuk ego durumlarının Yetişkin ego durumunu programlamasına neden olur. Bunun sonucunda kişi eldeki verilere göre davranmak yerine duruma uygun olmayan tepkiler vermektedir. Sonuç olarak Yetişkin ego durumu, kişiliğimizin akılcı yanıdır. Algılama, bellekte tutma, veri-işleme ve benzeri bilişsel etkiler, Yetişkin ego durumunun fonksiyonudur. Yetişkin yanımız sayesinden, yargılayıcı ve duygusal olmadan, aklımızın gerekli gördüğü davranışları sergileyebiliriz (Deniz, 2002).

Araştırmada $Y$ ego durumunun, problem çözme becerisi toplam puanı ile pozitif bir ilişki içinde olmayıp, Aceleci Yaklaşım (AY) problem çözme becerisi alt boyutu arasında pozitif anlamlı bir ilişki olduğu görülmüştür ( $P>0.05$; Tablo 4). Yüksek problem becerisine sahip olan bireylerin Yetişkin ( $Y$ ) ve Koruyucu Ebeveyn (KY) ego durumlarında anlamlı olarak yüksek puan ortalamasına sahip olduğunu Çam (1995) ifade etmiştir. Fakat $Y$ ego durumunun, problem çözme becerisi toplam puanı ile bir ilişki içinde olmayıp, AY problem çözme becerisi alt boyutu ile bir ilişki içinde olması literatür açısında çelişkili bir durum yaratmıştır. Bu durum sporcuların problem çözmede sorunlar yaşamasına ve diğer taraftan kişilik yönleri ve kişilerarası ilişkilerinde olumsuz bir tutum sergilemeleri bakımından muhtemel görülebilir.

Bireyin baskın ego durumu, onun yaşamını, kişiliğini ve kişilerarası ilişkilerini belirlediği gibi, yaşam içinde karşılaştığı sorunların çözüme kavuşturma konusunda da etkili bir rol oynamaktadır. Problemin çözülmesinde, $Y$ ego durumunun, Düşünen Yaklaşım (DY), Değerlendirici Yaklaşım (DRY), Kendine Güvenli Yaklaşım (KGY) ve Planlı Yaklaşım (PY) problem çözme becerisi alt boyutları ile bir ilişki içinde olması gerektiği konusunda bir beklenti içinde olmak, kuramsal açıdan yanlış değildir. Çünkü alt ölçeklerin puanlanmasında da olumlu-istendik olarak nitelendirilebilecek problem çözme yaklaşım biçimlerini ölçen alt ölçeklerden (Düşünen Yaklaşım, Kendine Güvenli Yaklaşım, Değerlendirici Yaklaşım, Planlı Yaklaşım) alınan puanlar azaldıkça ilgili yaklaşım biçimlerinin daha fazla kullanıldığı değerlendirilirken; olumsuz-etkisiz olarak nitelendirilebilecek problem çözme yaklaşım biçimlerini ölçen alt ölçeklerden (aceleci yaklaşım 
ve kaçıngan yaklaşım) alınan puanlar azaldıkça ilgili yaklaşım biçimlerinin daha az kullanıldığı düşünülür (Ferah, 2000). Araştırma sonuçlarının bu açıdan bir paralellik gösterdiğini söylemek doğru değildir.

Literatürde, bireysel sporcuların ve düzenli spor yapanların, takım sporu yapanlara göre problem çözme becerilerine daha düşük olduğu ve bu durumun takım sporlarının eğitici yanı ile ilişkili olabileceği ifade edilmiştir (Canan ve Ataoğlu, 2010). Fakat burada problem çözme becerisini bireysel ve takım sporları açısında salt bir değerlendirme içinde tutmak doğru olmayabilir. Çünkü her spor dalı farklı karakteristik oyun ve oynanma özelliklerine sahiptir. Bu bakımdan bireysel bir spor dalı olan masa tenisini de bu açıdan el almak gerekir. Masa tenisinin diğer sporlara nazaran çok daha hızlı oynanması ve çabuk karar verilip doğru hamlenin yapılması saniyeler ve saliselerle gerçekleşmektedir. Bu sebeple oyunun karakteristik özelliği sporcuların problem çözme becerisine yansıyabileceği düşünülebilir. Nitekim Spor ve kişilik arasında bir etkileşimin olduğu araştırmacılar arasında şüphe duyulmaz bir gerçektir (Allen ve diğ., 2013). Ayrıca farklı spor dalları, farkı kişilik özellikleri ile paralellik gösterdiği ile ilgili birçok araştırma literatürde mevcuttur (Yıldız, 2008; Allen ve diğ., 2013; Erdoğan ve Kocaekşi, 2015). Toplumsallaşma ve seçicilik hipotezlerine göre spor, kişiliği etkiler ve kişiliğin sadece yapılacak spor branşını değil, aynı zamanda bireyin spordaki başarısında da etkili olduğunu savunmaktadır (Bierhoff-Alfermann, 1986'dan akt., ikizler ve Karagözoğlu 1993). Sonuç olarak, araştırmada masa tenisi sporcularının Y ve DÇ ego durumlarının ile AY ve KY alt boyutları arasında bir ilişki içinde olması masa tenisi sporunun sporcuları üzerindeki bir etkisi olarak görülebilir. Fakat kuramsal temel açısında olumsuz bir durumun göstergesi olduğunun da altını çizmek gerekir.

\section{5. Öneriler}

Araştırmanın bir sonraki araştırmalara yol gösterebilmesi açısından bazı öneriler aşağıda ifade edilmiştir;

Araştırmanın sonuçları kuramsal temel açısında çelişki içinde olduğu görülmektedir. Bu sebeple ileriki araştırmaların farklı spor branşlarında alınıcak örneklem grupları ile gerçekleştirilmesi problem çözme becerisi ile ego durumları arasındaki ilişkinin daha iyi kavranabilmesini açısında önemlidir.

Problem çözme becerisinin, sporcuların ego durumları ile nasıl bir ilişki içinde olduğu dair veriler elde edilmesi açısından sadece Arı tarafından geliştirilen "Ego Durumları Ölçeği (EDÖ)" kullanılmıştır. Literatürde birey/bireylerin ego durumlarının belirlenmesinde farklı ölçekler mevcuttur. Bu bakımdan literatürdeki farklı ölçeklerin kullanılması farklı sonuçlar verebilir

Sporcuların kişilik özelliklerini ya da psikolojik becerilerini belirlemek için çeşitli araştırma yöntemleri kullanılmaktadır. Sporcuların kişilik özellikleri veya psikolojik berileri arasında ilişkinin incelenmesi açısından nitel araştırma ya da nicel ve nitel araştırma desenlerinin birlikte kullanıldığı tümleşik/karma araştırma yöntemlerinin kullanılması farklı bulgular ve bakış açıları sağlayabilir.

\section{Kaynakça}

Akkoyun, F. (2011). Transaksiyonel Analiz. Ankara: Nobel Yayın.

Allen, M. S., Greenlees, I., \& Jones, M. (2013). Personality in sport: A comprehensive review. International Review of Sport and Exercise Psychology, 6(1), 184-208.

Arı, R. (1989). Üniversite öğrencilerinin baskın ben durumları ile bazı özlük niteliklerinin, ben durumlarına, atılganlık ve uyum düzeylerine etkisi. Doktora Tezi, Hacettepe Üniversitesi Sosyal Bilimler Enstitüsü, Ankara.

Atasoy, F. S. (2019). Genç amatör futbolcuların transaksiyonel analize dayalı ego durumları ve takım mevkileri bağdaşım düzeylerinin performansları ile ilişkisi: Samsun ili örneği. Yüksek Lisans Tezi, Ondokuz Mayıs Üniversitesi Sosyal Bilimler Enstitüsü, Samsun.

Baştuğ, G. (1993). Histerik kadınların ve eşlerinin kendilerini ve birbirlerini algılamalarının karşılaştırılması (TA Ego Durumları bakımından). Yüksek Lisans Tezi, Ankara Üniversitesi Sosyal Bilimler Enstitüsü, Ankara.

Berne, E. (2015). İnsanların Oynadığı Oyunlar. (Çev. Handan Ünlü Haktanır), İstanbul: Koridor Yayıncılık.

Stewart, I., \& Joines V. (2017). Günümüzde TA, Transaksiyonel Analiz'e Yeni Bir Bakış. (Çev. Edt. Füsun Akkoyun), Ankara: Eksi Kitaplar.

Canan, F., \& Ataoğlu, A. (2010). Anksiyete, depresyon ve problem çözme becerisi algısı üzerine düzenli sporun etkisi. Anatolian Journal of Psychiatry, 11, 38-43. 
Çam, S. (1995). Öğretmen adaylarının ego durumları ile problem çözme becerisi algısı ilişkisinin incelenmesi. Türk Psikolojik Danışma ve Rehberlik Dergisi, 2, 6.

Demircan, Y. (2018). Beden eğitimi öğretmenlerinin, problem çözme becerileri karar verme stilleri ve örgütsel bağ|lık düzeyleri. Yüksek Lisans Tezi, Karadeniz Teknik Üniversitesi Eğitim Bilimleri Enstitüsü, Trabzon.

Deniz, M. E. (2002). Üniversite öğrencilerinin karar verme stratejileri ve sosyal beceri düzeylerinin TA- baskın ben durumları ve bazı özlük niteliklerine göre karşılaştırılmalı olarak incelenmesi. Doktora Tezi, Selçuk Üniversitesi Sosyal Bilimler Enstitüsü, Konya.

Erdoğan, N., \& Kocaekşi, S. (2015). Elit sporcuların sahip olması gereken psikolojik özellikler. Türkiye Klinikleri Spor Bilimleri Dergisi, 7(2), 57-64.

Ferah, D. (2000). Kara harp okulu öğrencilerinin problem çözme becerilerini algılamalarının ve problem çözme yaklaşım biçimlerinin cinsiyet, sınıf, akademik başarı ve liderlik yapma açısından incelenmesi. Yayınlanmamış Yüksek Lisans Tezi, Hacettepe Üniversitesi, Ankara.

Gülşen, D. (2008). Farklı lig düzeyinde oynayan futbolcuların oynadıkları mevkilere, öğrenim durumu ve spor yaşlarına göre problem çözme becerilerinin incelenmesi. Yüksek Lisans Tezi, Çukurova Üniversitesi Sağlık Bilimleri Enstitüsü, Adana.

Harris, T. (2018). Ben OK'im Sen OK'sin. (Çev. Edt. Muzaffet Şahin), İstanbul: Okuyan Us Yayıncılık.

Heppner, P. P., \& Petersen, C. H. (1982). The development and implications of a personal problem-solving inventory. Journal of counseling psychology, 29(1), 66-75.

íkizler, H. C., \& Karagözoğlu, C. (1993). Sporda Başarının Psikolojisi. İstanbul: Alfa Basım Yayın.

İnce, G., \& Şen, C. (2006). Adana İl'inde deplasmanlı ligde basketbol oynayan sporcuların problem çözme becerilerinin belirlenmesi. Spormetre Beden Eğitimi ve Spor Bilimleri Dergisi, 4(1), 5-10.

Karasar, N. (2006 ). Bilimsel aştırma Yöntemi. Ankara: Nobel yayın Dağıtım.

Oğuzkan, F. (1989). Orta Dereceli Okullarda Öğretim. Ankara: Emel Matbaacılık.

Öztürk, A., Bayazıt, B., \& Gencer, E. (2016). Judocuların problem çözme becerilerinin ve sportif güven düzeylerinin incelenmesi (Trabzon olimpiyat hazırlık merkezi örneği). Spormetre Beden Eğitimi ve Spor Bilimleri Dergisi, 14(2), 145-151.

Pulur, A. Karabulut, E. O., \& Koç, H. (2012). Farklı branşlardaki üst düzey üniversiteli sporcuların problem çözme becerilerinin incelenmesi. Spormetre Beden Eğitimi ve Spor Bilimleri Dergisi, 10(1), 1-6.

Savaşır, I., \& Şahin, N. H. (1997). Bilişsel ve davranışçı terapilerde değerlendirme: Sık kullanılan ölçekler. Ankara: Türk Psikologlar Derneği Yayınları.

Sahin, N., Sahin, N. H., \& Heppner, P. P. (1993). Psychometric properties of the problem solving inventory in a group of Turkish university students. Cognitive Therapy and Research, 17(4), 379-396.

Solomon, C. (2003). Transactional analysis theory: The basics. TAJ., 33(1), 15-22.

Taylan, S. (1990). Heppner'in Problem Çözme Envanteri'nin Uyarlama, Geçerlik ve Güvenirlik Çalışmaları. Yüksek lisans tezi, Ankara Üniversitesi Sosyal Bilimler Enstitüsü, Ankara.

Thornton, S. (1998). Çocuklar Problem Çözüyor. (Çev: Özlem Kumrular), İstanbul:Gendaş yayınları.

Yiğiter, K. (2012). Rekreatif etkinliklerin üniversite öğrencilerinde algılanan problem çözme becerisi ve benlik saygısı düzeylerine etkisi. Doktora Tezi, Kocaeli Üniversitesi Sağlık Bilimleri Enstitüsü, Kocaeli.

Yıldız, M. (2008). Farklı liglerde yer alan futbolcuların kişilik tipleri ile sürekli öfke-öfke ifade tarzlarının incelenmesi. Doktora Tezi, Gazi Üniversitesi Sağlık Bilimleri Enstitüsü, Ankara. 